\title{
Influence of Aggregate Coated with Modified Sulfur on the Properties of Cement Concrete
}

\section{Swoo-Heon Lee ${ }^{1}$, Ki-Nam Hong ${ }^{2, *}$, Jae-Kyu Park ${ }^{2}$ and Jung Ko ${ }^{3}$}

1 Department of Civil Engineering, University of Texas at Arlington, Arlington, TX 76019, USA;

E-Mail: swooheon@uta.edu

2 School of Civil Engineering, Chungbuk National University, Chungbuk 361-763, Korea;

E-Mail:kaga0618@hanmail.net

3 Railway Inspection Section, Korea Infrastructure Safety \& Technology Corporation, Gyeonggi 411-758, Korea; E-Mail: kjungk33@hanmail.net

* Author to whom correspondence should be addressed; E-Mail: hong@chungbuk.ac.kr; Tel.: +82-43-261-2378; Fax: +82-43-275-2377.

Received: 21 April 2014; in revised form: 10 June 2014 / Accepted: 10 June 2014 /

Published: 20 June 2014

\begin{abstract}
This paper proposes the mixing design of concrete having modified sulfur-coated aggregate (MSCA) to enhance the durability of Portland cement concrete. The mechanical properties and durability of the proposed MSCA concrete were evaluated experimentally. Melting-modified sulfur was mixed with aggregate in order to coat the aggregate surface at a speed of $20 \mathrm{rpm}$ for $120 \mathrm{~s}$. The MSCA with modified sulfur corresponding to $5 \%$ of the cement weight did not significantly affect the flexural strength in a prism concrete beam specimen, regardless of the water-cement ratio (W/C). However, a dosage of more than $7.5 \%$ decreased the flexural strength. On the other hand, the MSCA considerably improved the resistance to the sulfuric acid and the freezing-thawing, regardless of the sulfur dosage in the MSCA. The coating modified sulfur of 5\% dosage consequently led to good results for the mechanical properties and durability of MSCA concrete.
\end{abstract}

Keywords: modified sulfur; coated aggregate; durability; strength; freezing-thawing; acid resistance 


\section{Introduction}

Reinforced concrete has been widely used as construction material due to its versatility. However, several factors can cause the deterioration of concrete structures. Currently, abnormal climate and air pollution have accelerated the deterioration of concrete structures. The main factors behind the deterioration of concrete are considered to be the salt damage, carbonation, chemical erosion, frost damage, and drying shrinkage. The deterioration leads to steel corrosion and sectional-area reduction. Thus, such damage can cause the collapse of structures because it can result in strength loss and unsafe conditions. Neville explained the mechanisms of concrete deterioration [1]: (1) Carbonation - concrete carbonation results when $\mathrm{CO}_{2}$ reacts with $\mathrm{Ca}(\mathrm{OH})_{2}$. Carbonation starts on the concrete surface and moves slowly to the interior of the concrete because $\mathrm{CO}_{2}$ in the air penetrates to the interior of the concrete through capillarity in the cement paste; (2) Corrosion-steel reinforcements can be destroyed by chloride ions that penetrate the concrete; (3) Freeze and thaw cycles-because concrete is porous, water is trapped and absorbed in the pores. The increased volume of water can lead to cracking when the water in concrete freezes; (4) Sulfate attack - the soluble sulfates in groundwater may react with a hydrate from cement. Wang et al. [2-5] recently carried out a research project titled "Analysis of Climate Change Impacts on the Deterioration of Concrete Infrastructure", in Australia. The report included (i) a review of the mechanisms, practice, modeling, and simulations of concrete deterioration; (ii) modeling and simulations of concrete deterioration processes and adaptation options; and (iii) case studies of concrete deterioration and adaption. Although the extent of damage due to deterioration differs from country to country because the climate and environmental conditions vary, research to prevent the deterioration of concrete has become a great shared interest. Particularly, research on how to integrate industrial waste into the concrete mix has been conducted to improve the durability of concrete [6-9].

Attempts to use sulfur as a construction material began around 1921 to consume the surplus sulfur from a mine named Big Doom in Texas, USA. Bacon and Davis [10] found that the mixture of $60 \%$ sand and $40 \%$ sulfur had high strength and acid resistance. However, the sulfur concrete had problems of flexural strength reduction, cubic expansion, and micro-crack occurrence due to repeated temperature changes. To overcome these problems, studies on the modification of sulfur have been carried out by many researchers [11-13]. Their sulfur modifier systems were a mixture of dicyclopentadiene and oligomers of cyclopentadiene or dicyclopentadiene, and the melting temperatures of their modified sulfur were in the range of $118-140^{\circ} \mathrm{C}$. Sulfur concrete has several advantages over Portland cement concrete [14-18]: (1) its resistance to broadly-based acid and salinity is high; (2) the required mechanical property can be manifested in $24 \mathrm{~h}$ due to its fast hardening; (3) it has high tensile, compressive, and flexural strength as well as high fatigue resistance; (4) it can be manufactured all-year-round or even in subfreezing weather; (5) it can be used as a waterproof material due to the hydrophobicity of sulfur; and (6) it has always been recyclable. Thus, sulfur concrete can be used as a replacement material for Portland cement not only in places where acid and salinity can cause damage but also in places with extreme climate where freezing-thawing can repeatedly occur [16].

Recently, studies to improve the mechanical properties and durability of concrete by using a coating aggregate have also been conducted. Li et al. [19] found that a coating recycled aggregate with pozzolanic powder improved the concrete slump, compressive strength, flexural strength, and precision 
in the interfacial transition zone (ITZ) compared to Portland cement concrete. Kong et al. [20] proposed a triple mixing method (TM) to realize surface-coating aggregate using pozzolanic materials. This method enhanced the strength and durability of recycled aggregate concrete more than when a double mixing method (DM) was used. Compared to concrete with dispersed latex polymer in the bulk past, the fracture energy was increased in the concrete with a latex polymer-coated aggregate by Morin et al. [21]. The compressive strength in the pre-coating recycled aggregate concrete was increased by $10 \%$ with an increased water-cement ratio in comparison with the control concrete. The coating was found to reduce the strength loss of mortar through a sulfate attack test conducted by Zhihui et al. [22].

To use sulfur as a construction material, it is necessary to heat the aggregate and filler as well as to melt the modified sulfur at high temperature [16]. The heating cost has been an impediment to the application of sulfur in large-scale construction sites. In this study, a modified sulfur-coated aggregate (MSCA) concrete was designed to integrate the acid resistance and freezing-thawing resistance of sulfur into Portland cement concrete. The performance of the MSCA concrete was evaluated experimentally.

\section{Test Results and Discussion}

\subsection{Properties of Hardened Concrete}

The water absorptions of R40-CON, R40-NS5, R40-NS7.5, and R40-NS10 were 3.38\%, 4.17\%, $4.18 \%$, and $4.20 \%$, respectively. And the total porosities of corresponding admixtures were $7.74 \%$, $9.48 \%, 9.67 \%$, and $10.06 \%$, severally. It was confirmed, from test results, that the MSCA increased both absorption and porosity of concrete, but the modified sulfur content at the coated aggregates slightly affected them. This result can be explained as followings: (1) the coated aggregate with modified sulfur causes its absorption to be reduced; (2) the space occupied by surplus water forms the high porosity in the MSCA concrete. The bulk densities of R40-CON, R40-NS5, R40-NS7.5, and R40-NS10 were $2.29,2.26,2.26$, and $2.25 \mathrm{Mg} / \mathrm{m}^{3}$, respectively. Those were not much different regardless of amount of modified sulfur.

\subsection{Compressive Strength}

Figure 1 shows the compressive strength changes in the concrete cylinders with MSCAs, which were coated with various amounts of sulfur, in relation to $\mathrm{W} / \mathrm{C}$ and curing time. The compressive strengths shown in Figure 1 are the average values of three specimens for each mixture. For admixtures with W/C ratio of 40\%, the compressive strengths of R40-NS5, R40-NS7.5 and R40-NS10 at a 7 -day age had decreased by $19 \%, 23 \%$ and $28 \%$ relative to R40-CON, respectively (see Figure 1a). At a 28-day age, the compressive strength of corresponding admixtures decreased by $6 \%, 20 \%$, and $32 \%$. At 56 days, these values had decreased to $5 \%, 18 \%$, and $33 \%$. The reduction rate of compressive strength of R40-NS5 decreased with passing curing age, whereas those of R40-N7.5 and R40-N10 were almost constant regardless of curing age. It was obvious from test results that the high dosage of modified sulfur may cause the cement setting problem and thus could delay the hydration process in concrete. 
Figure 1. Compressive strength of cylinders with (a) water-cement ratio (W/C) of $40 \%$;

(b) $\mathrm{W} / \mathrm{C}$ of $45 \%$; and (c) $\mathrm{W} / \mathrm{C}$ of $50 \%$ with respect to $\mathrm{W} / \mathrm{C}$ and curing time.

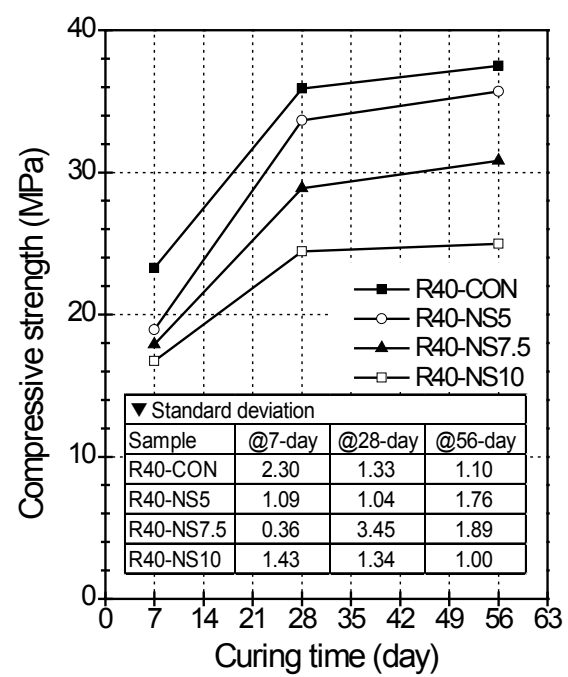

(a)

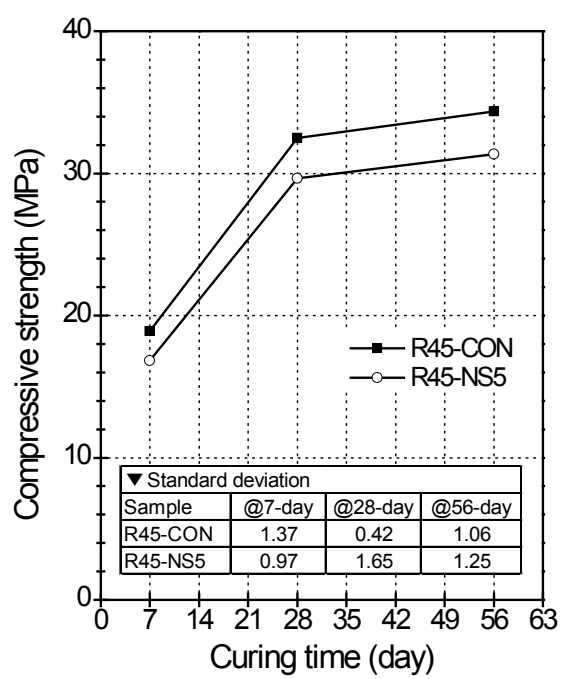

(b)

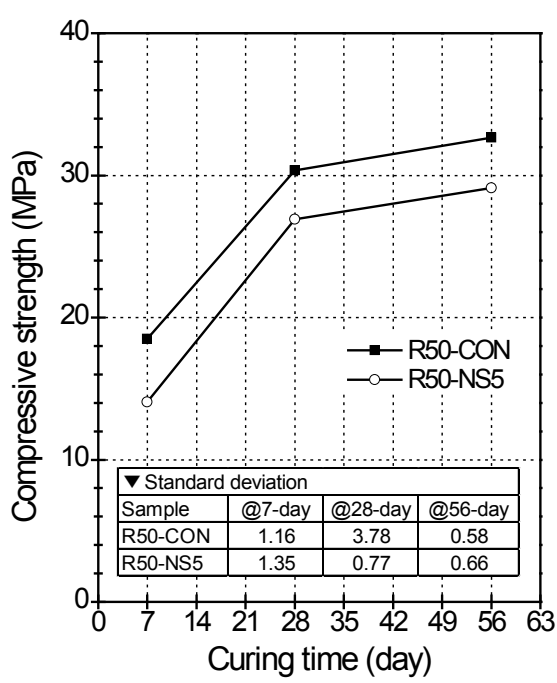

(c)

The compressive strength of the MSCA concrete decreased further when a higher amount of modified sulfur was used to coat the aggregate. There could be three reasons: (1) the remains of coated sulfur can act as impurities or light-weight aggregate in the concrete; (2) the additional quantity of superplasticizer needed to obtain an identical slump in concrete with more sulfur can lead to the formation of more pores in the cement paste; (3) the more amounts of modified sulfur owing to its low stiffness and strength result in the weaker microstructure of ITZ, leading to a decreased compressive strength.

Of the specimens with 5\% MSCA, the compressive strengths at 56 days in R40-NS5, R45-NS5, and R50-NS5 cylinder samples (see Figure 1b,c) had decreased by 5\%, 9\%, and 11\% from that of each control sample with normal aggregate. In other words, the compressive strength tended to decrease with an increased W/C. A possible explanation is that the surplus of modified sulfur may have a greater effect on the strength of concrete with a higher $\mathrm{W} / \mathrm{C}$ because the amount of cement decreased with the higher $\mathrm{W} / \mathrm{C}$.

\subsection{Flexural Strength}

The flexural strengths of the prism beams are plotted in Figure 2. The strengths shown in Figure 2 are the averaged values of three specimens for each mixture. The flexural strengths at 28 and 56 days were almost the same for each W/C. Of the specimens with a W/C of $40 \%$ (see Figure $2 \mathrm{a}$ ), the strength at 28 days of R40-NS5 had increased by about $0.7 \%$ as compared to the control specimen of R40-CON. On the contrary, the strengths at 28 days of the others had decreased up to $15 \%-16 \%$. The results of this experiment are in agreement with the experimental result obtained in a study by Morin et al. [21], which used latex-coated aggregate. The flexural strength loss in the concrete with aggregate coated by more than $7.5 \%$ of modified sulfur may have the same explanation as the loss of compressive strength discussed above. 
Figure 2. Flexural strength of prism beams with (a) W/C of $40 \%$; (b) W/C of $45 \%$; and (c) $\mathrm{W} / \mathrm{C}$ of $50 \%$ in relation to $\mathrm{W} / \mathrm{C}$ and curing time.

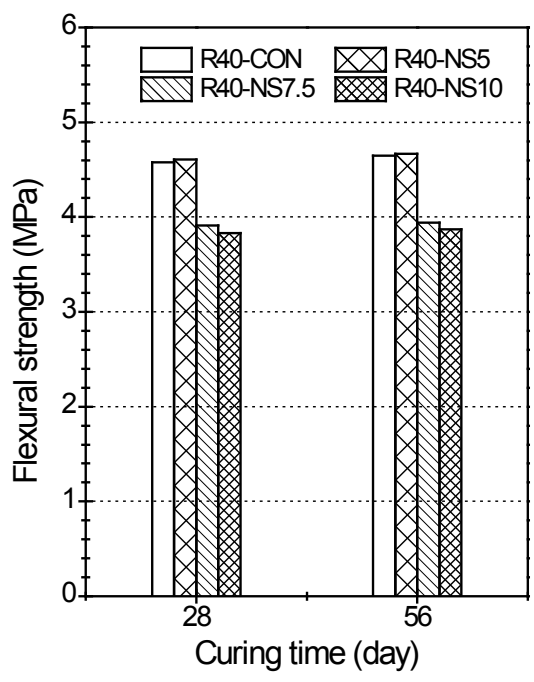

(a)

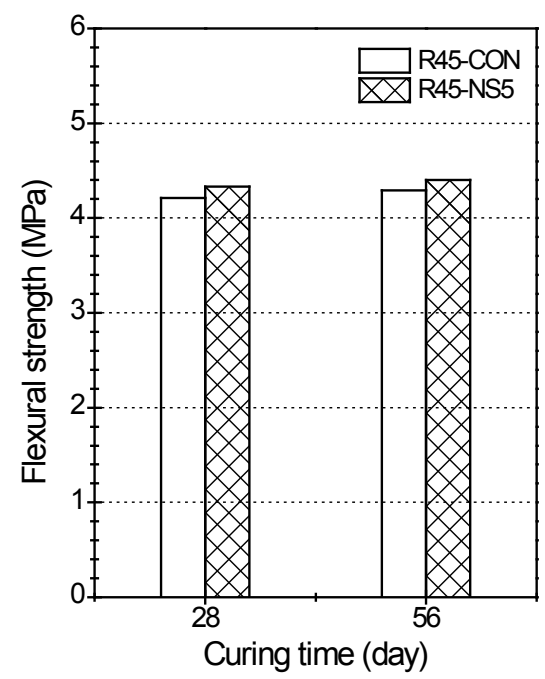

(b)

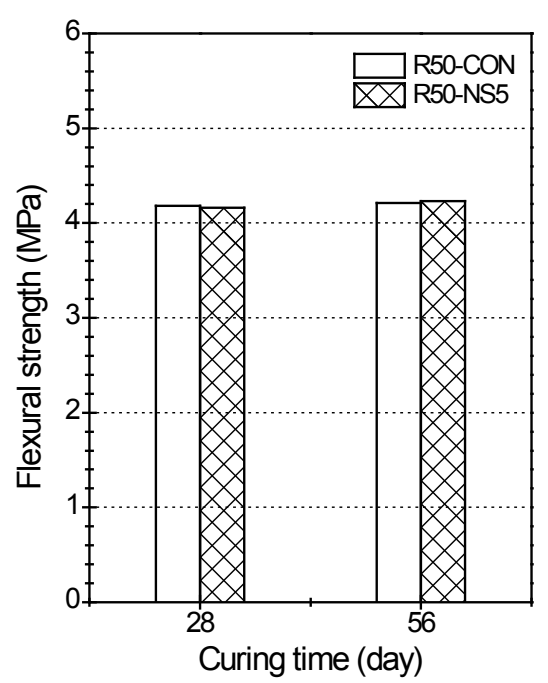

(c)

Additionally, the flexural strengths at 56 days of specimens with different W/C and 5\% MSCA had increased when compared with each control sample, but the variation rate was slight (e.g., $0.4 \%$ for $\mathrm{W} / \mathrm{C}=40 \%, 2.6 \%$ for $\mathrm{W} / \mathrm{C}=45 \%$ and $0.5 \%$ for $\mathrm{W} / \mathrm{C}=50 \%$ ). In other words, the $5 \%$ MSCA did not significantly affect the flexural strength loss regardless of $\mathrm{W} / \mathrm{C}$.

\subsection{Length Change}

The length change of concrete with passing time is presented in Figure 3. The averaged length changes of R40-CON, R40-N45, R40-N7.5, and R40-N10 admixtures at 7-day age were $-2.50 \times 10^{-4}$, $-2.10 \times 10^{-4},-2.03 \times 10^{-4}$, and $-2.17 \times 10^{-4} \mathrm{~mm} / \mathrm{mm}$, repetitively (see Figure $3 \mathrm{a}$ ). The MSCA led to a slight decrease of length change, but the amount of modified sulfur at the MSCA did not significantly affect the length change. At the age of 56 days, the length changes of corresponding admixtures had increased by $-6.57 \times 10^{-4},-6.47 \times 10^{-4},-6.50 \times 10^{-4}$, and $-6.53 \times 10^{-4} \mathrm{~mm} / \mathrm{mm}$, respectively (see Figure 3a). The length change of MSCA concrete increased with the higher content of modified sulfur, but it was determined that the modified sulfur had little effect on the length changes because the change rates of MACA concrete were almost similar to that of R40-CON specimen. The length changes at 7-56 days in specimens having a W/C of 45\% (see Figure $3 \mathrm{~b}$ ) were greater in each control sample than in the specimen with the MSCA. On the other hand, the length changes of two specimens with a 50\% W/C (see Figure 3c) went up and down until 28 days. After 28 days of curing, the length changes of two specimens were almost identical. Based on the length change observations, it was found that the length change due to the MSCA was slightly smaller than or equal to that of the control specimens. 
Figure 3. Length change of prism beams with (a) W/C of $40 \%$; (b) W/C of $45 \%$; and (c) $\mathrm{W} / \mathrm{C}$ of $50 \%$ in relation to $\mathrm{W} / \mathrm{C}$ and curing time (unit: $\mathrm{mm} / \mathrm{mm}$ ).

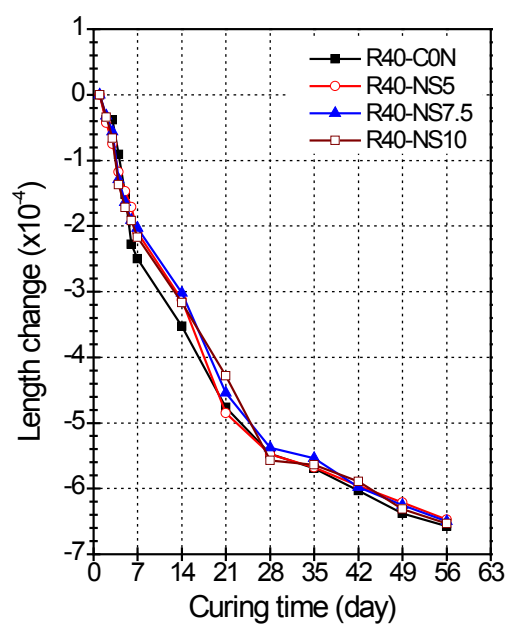

(a)

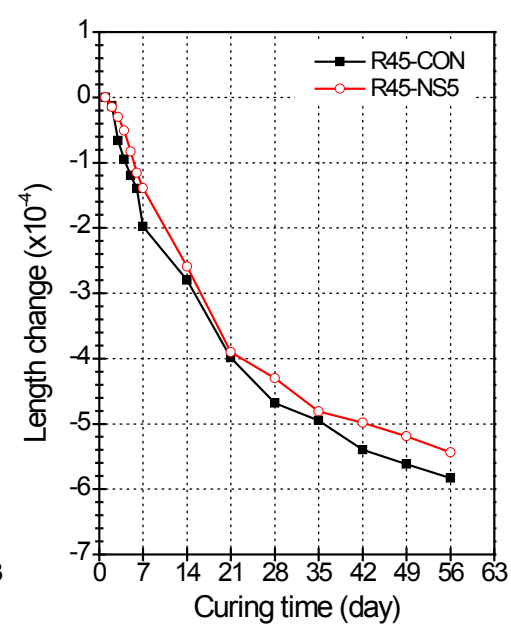

(b)

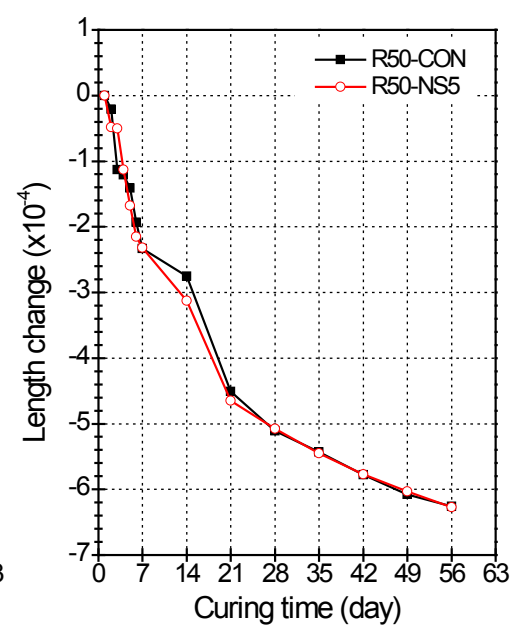

(c)

\subsection{Freezing and Thawing}

The relative dynamic modulus of elasticity and weight change in the freezing and thawing test are presented in Figures 4 and 5, respectively. The freezing and thawing test was carried out using the prism beam specimens with only $\mathrm{W} / \mathrm{C}$ of $40 \%$. The freezing and thawing test was performed for only admixtures with a W/C of $40 \%$ because of the capacity of equipment. After 30 cycles of lowering and raising the temperature, the relative dynamic modulus of elasticity became $91.0 \%$ in beam R $40-\mathrm{CON}$, 91.9\% in R40-NS5, 92.1\% in R40-NS7.5, and 92.8\% in R40-NS10, respectively. The relative dynamic modulus of elasticity changed to $88.1 \%, 92.7 \%, 91.8 \%$, and $90.9 \%$ at 150 cycles. That in beam R40-CON with normal aggregate rapidly decreased after 150 cycles, and then it reached 61.4\% at 300 cycles. However, the relative dynamic modulus of elasticity of the specimens with the MSCA barely changed while maintaining the range of $90 \%-95 \%$.

The weight losses for each sample (e.g., R40-CON, R40-NS5, R40-NS7.5 and R40-NS10 prism beams) were $0.17 \%, 0.16 \%, 0.0 \%$ and $0.14 \%$ at 30 cycles, respectively. When 300 cycles passed, the weight losses in each sample were $2.8 \%, 1.4 \%, 1.23 \%$ and $1.2 \%$. The loss of the control specimen was almost twice as large as that of the MSCA concrete. The weight losses of the MSCA concrete with different amounts of sulfur were not significantly different.

Figure 6 shows the corrosion changes of four samples (e.g., R40-CON, R40-NS5, R40-NS7.5 and R40-NS10 prism beams) with passing cycles.

The surface of the R40-CON sample started popping out considerably from 90 cycles, and exposure of the aggregate in the concrete was seen plainly after 180 cycles had passed. On half of the surface, aggregate exposure developed after 300 cycles, as illustrated in Figure 6a. In the MSCA concrete, the initial porosity faded after 300 cycles, but aggregate exposure due to popping out never occurred, as shown in Figure 6b-d. Based on the surface porosity observation, the MSCA significantly improved the freezing and thawing resistance. It was observed that the corrosion progress in R40-CON had been visually much more rapid than that in samples with MSCA. When water freezes, a volume expansion of $9.1 \%$ occurs, and the expansion moves to opening gap in cement paste. If there are no pores, mainly 
caused by entrained air, to relax the expansion, high pressure builds up in the concrete, and this is one cause of deterioration. Therefore, it was obvious that the use of MSCA results in the high porosity in the concrete and thus develops the resistance against the freezing and thawing of concrete.

Figure 4. Relative dynamic modulus of elasticity by freezing-thawing cycles.

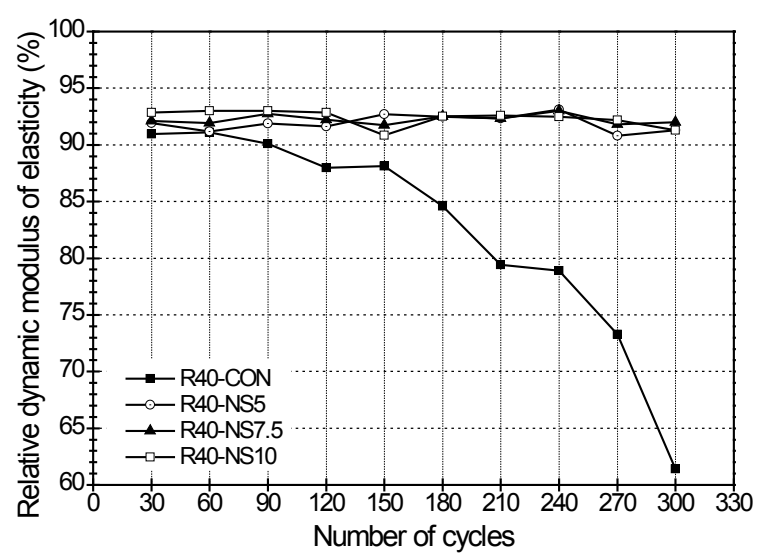

Figure 5. Weight change by freezing-thawing cycles.

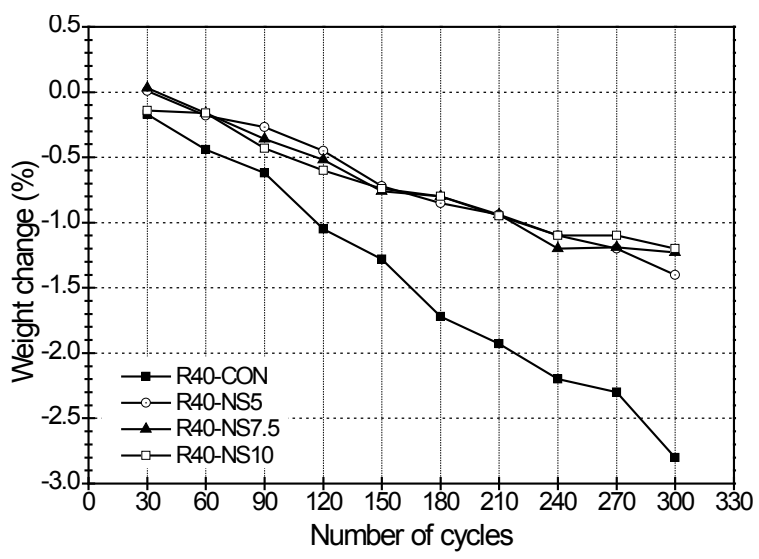

Figure 6. Surface status of (a) R40-CON; (b) R40-NS5; (c) R40-NS7.5; and (d) R40-NS10 specimens according to number of cycles.

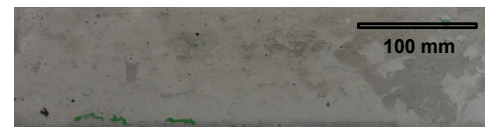

0 cycle

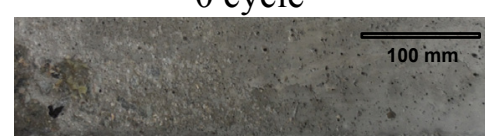

90 cycles

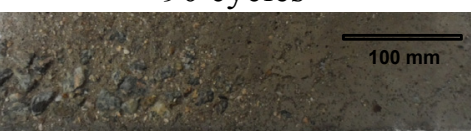

210 cycles

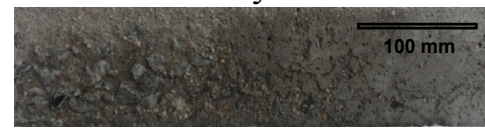

300 cycles

(a)

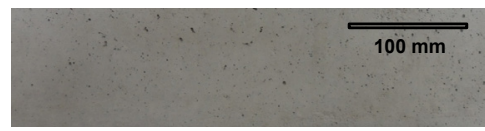

0 cycle

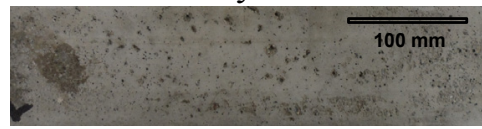

90 cycles

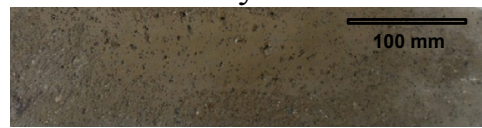

210 cycles

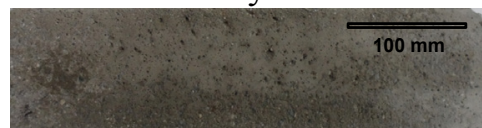

300 cycles

(b) 
Figure 6. Cont.

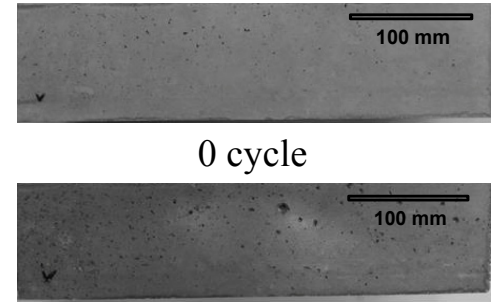

90 cycles

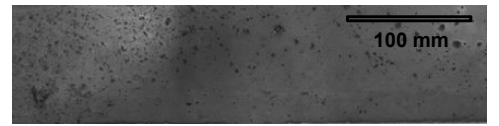

210 cycles

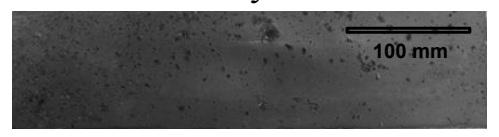

300 cycles

(c)

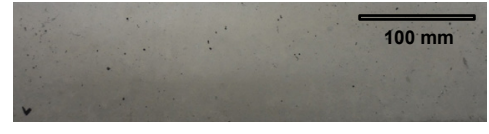

0 cycle

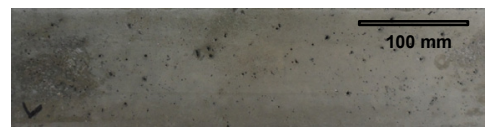

90 cycles

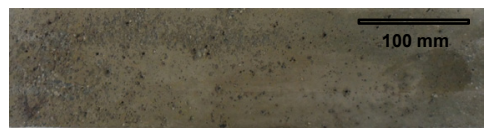

210 cycles

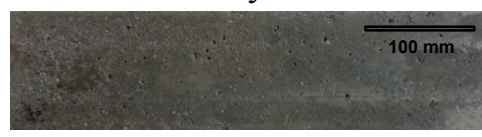

300 cycles

(d)

\subsection{Sulfate Resistance}

The resistance of the MSCA concrete to sulfuric acid was investigated every 7 days for 4 weeks. The effect of MSCA on the sulfate attack resistance of concrete is shown in Figure 7. Of the samples with $\mathrm{W} / \mathrm{C}=40 \%$ (see Figure 7a), the weight in only RS40-CON with normal aggregate decreased by $1.5 \%$ after 1 week of immersion; however, that of the other samples with MSCA increased up to about $2 \%$ after 1 week. The weight increase may have been caused by absorption of the liquid phase due to concrete surface porosity. After that, the weight in all samples decreased gradually until 4 weeks. The final weight loss of the sample with normal aggregate was around $9 \%$ but those of the samples with MSCA were $1.2 \%-1.6 \%$. There was little mass change, and it was insignificant for the samples with MSCA. It is known that the dilute hydrochloric and sulfuric acids, in general, cannot affect the sulfur. The sand and aggregate used in the concrete mixture consisted of mineral oxides of alkalinity. Acid damage on concrete is started from the chemical reactions of basic oxides, acid oxides, and amphoteric oxides. Because the coating modified sulfur prevents reaction between acid and basic oxides, the resistance to sulfate improves.

As compared to samples having MSCA with 5\% modified sulfur, the weight losses were $1.2 \%$ in the $\mathrm{W} / \mathrm{C}=40 \%, 1.0 \%$ in the $\mathrm{W} / \mathrm{C}=45 \%$, and $0.3 \%$ in the $\mathrm{W} / \mathrm{C}=50 \%$ samples after 4 weeks of immersion. Even though the loss of weight in two samples (R45-CON andR50-CON) with uncoated aggregate was not significantly different, the weight loss tended to be reduced with increased W/C. As test results, a higher $\mathrm{W} / \mathrm{C}$ enhanced the acid resistance of the modified sulfur concrete.

Corrosion probably developed on the sample surfaces in open pores that were not coated or protected by sulfur and lasted until the test ended (see Figure 8). The specimen of R40-CON immersed in sulfuric acid solutions for 4 weeks showed high corrosion. By contrast, the specimens with MSCA showed few signs of corrosion. This indicates that MSCA contributes to better acid resistance in comparison with the control sample with normal aggregate. 
Figure 7. Weight change of cylinders with (a) W/C of $40 \%$; (b) W/C of $45 \%$; and (c) $\mathrm{W} / \mathrm{C}$ of $50 \%$ in relation to $\mathrm{W} / \mathrm{C}$ and immersion time.

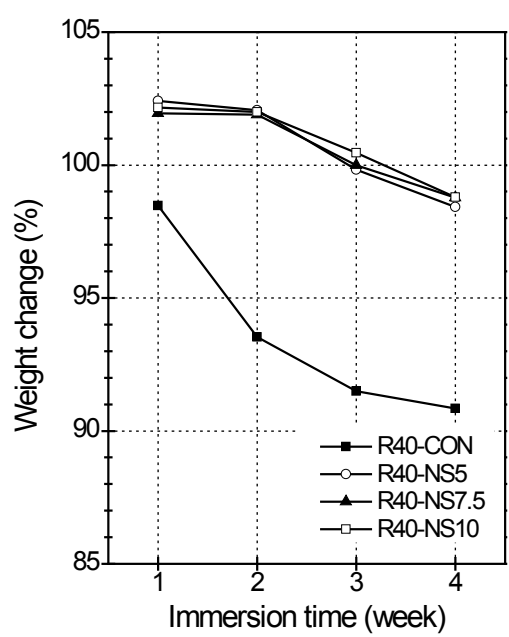

(a)

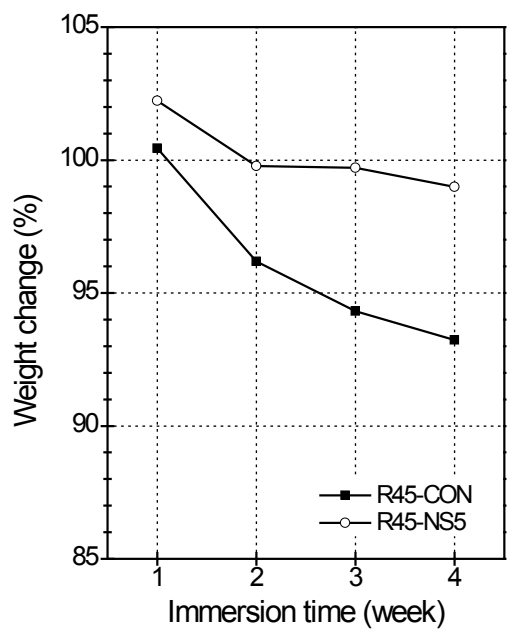

(b)

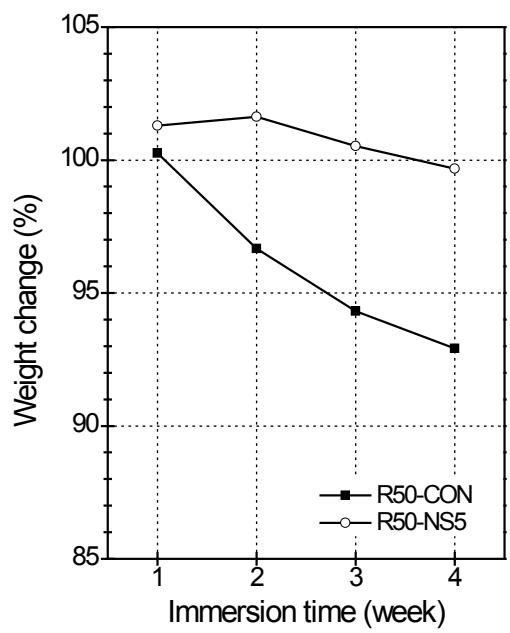

(c)

Figure 8. Surfaces of (a) R40-CON; (b) R40-NS5; (c) R40-NS7.5; and (d) R40-NS10 samples after 4 weeks of immersion in sulfuric acid.

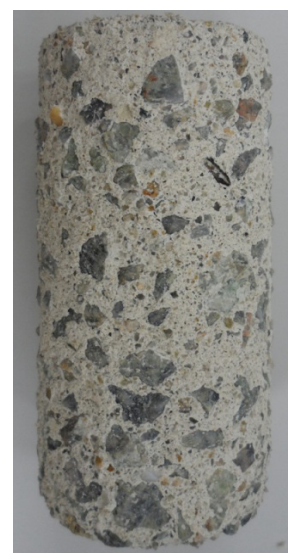

(a)

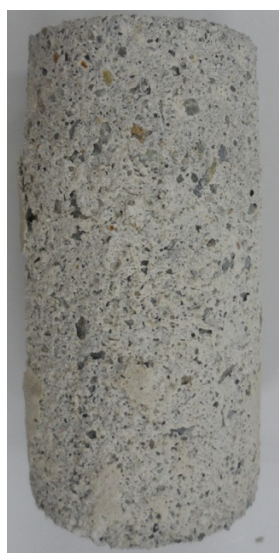

(b)

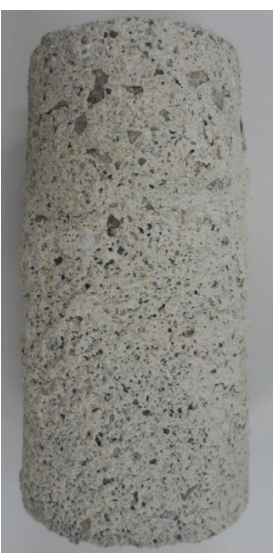

(c)

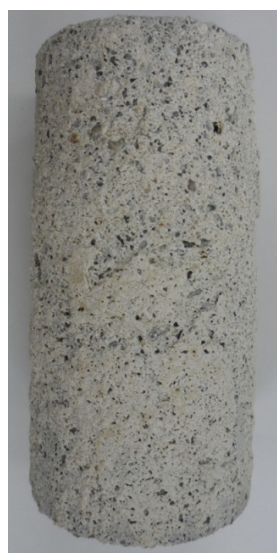

(d)

\section{Experimental Program}

\subsection{Materials}

Type I Ordinary Portland Cement (OPC) conforming to the Korean standard was used in mixture designs, and the density and specific surface area of the cement were $3.15 \mathrm{~g} / \mathrm{cm}^{3}$ and $3340 \mathrm{~cm}^{2} / \mathrm{g}$, respectively. OPC has an average compressive strength of $50.2 \mathrm{MPa}$ at a 28-day age. Its various chemical composition and physical properties are summarized in Tables 1 and 2, respectively.

Table 1. Chemical composition of Type I Ordinary Portland Cement.

\begin{tabular}{|c|c|c|c|c|c|c|c|c|}
\hline \multicolumn{8}{|c|}{ Chemical composition $(\%)$} & \multirow{2}{*}{$\begin{array}{c}\text { Loss } \\
\text { Ignition }\end{array}$} \\
\hline $\mathrm{SiO}_{2}$ & $\mathrm{CaO}$ & $\mathbf{A l}_{2} \mathbf{O}_{3}$ & $\mathrm{Fe}_{2} \mathrm{O}_{3}$ & MgO & $\mathrm{SO}_{3}$ & $\mathbf{K}_{2} \mathbf{O}$ & $\mathrm{Na}_{2} \mathrm{O}$ & \\
\hline 21.74 & 62.79 & 5 & 3.17 & 2.97 & 1.67 & 1.36 & 0.11 & 1.19 \\
\hline
\end{tabular}


Table 2. Physical properties of Type I Ordinary Portland Cement.

\begin{tabular}{|c|c|c|c|c|c|c|}
\hline \multicolumn{2}{|c|}{ Setting time (min) } & \multicolumn{3}{|c|}{ Compressive strength (MPa) } & \multirow{2}{*}{$\begin{array}{c}\text { Blaine specific } \\
\text { surface area }\left(\mathrm{cm}^{2} / \mathrm{g}\right)\end{array}$} & \multirow{2}{*}{$\begin{array}{c}\text { Specific } \\
\text { gravity }\end{array}$} \\
\hline Initial Setting & Final Setting & (a) 3-day & (a) 7-day & @ 28-day & & \\
\hline 221 & 303 & 30.32 & 41.50 & 50.20 & 3340 & 3.15 \\
\hline
\end{tabular}

The physical properties of the modified sulfur, aggregates and superplasticizer used in this experiment were summarized in Tables 3-5. The modified sulfur was manufactured by polymerization with sulfur, dicyclopentadiene, and amine compound. The specific gravity was 1.75 , the viscosity was $0.045 \mathrm{mPa} \cdot \mathrm{s}$ at $85^{\circ} \mathrm{C}$, the polymerization degree was from 300 to $1200 \mathrm{~g} / \mathrm{mol}$, the melting temperature of sulfur was $80^{\circ} \mathrm{C}$, and the ratio of modified sulfur was $99.3 \%$ (Note that this ratio was measured by gel permeation chromatography, which is capable of measuring polymers from 500 to 10 million Daltons). The fine aggregate used in the concrete was natural river sand with a specific gravity of 2.60, a fineness modulus of 2.99 , and water absorption of $2.90 \%$. The granite coarse aggregate was crushed with a maximum particle size of $20 \mathrm{~mm}$ for the concrete mixture. Crushed aggregate has a specific gravity of 2.63, a fineness modulus of 7.03, and water absorption of $1.01 \%$, which were measured according to ASTM C128 [23]. Figure 9 shows the grain size distribution of the aggregates used in the mix. Naphthalene superplasticizer was used to meet the target slump of $150 \pm 25 \mathrm{~mm}$.

Figure 9. Grain size distribution of fine and coarse aggregate.

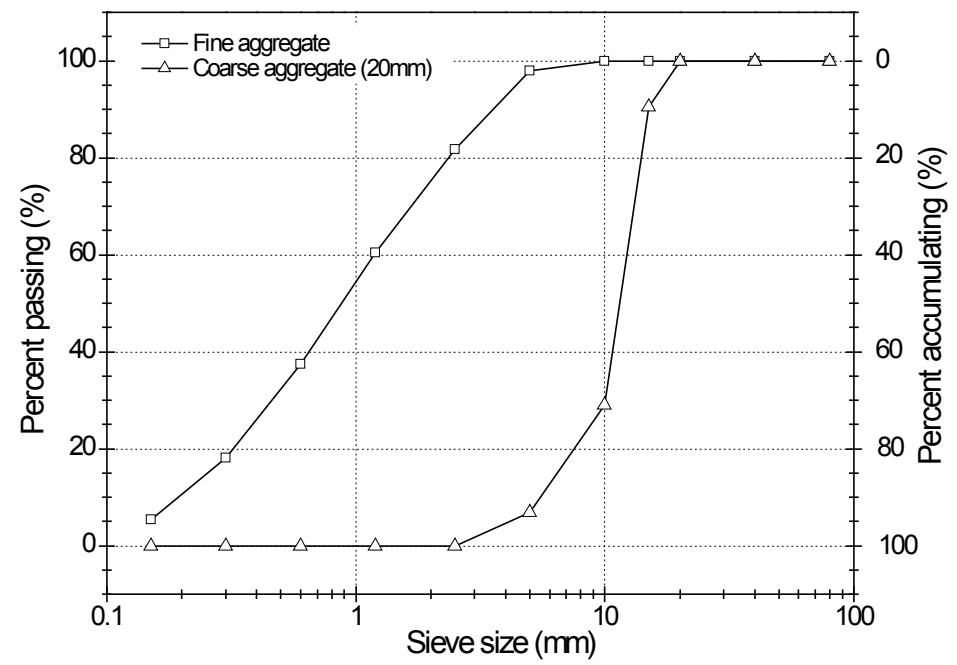

Table 3. Physical properties of modified sulfur.

\begin{tabular}{cccccc}
\hline Samples & $\begin{array}{c}\text { Specific } \\
\text { gravity }\end{array}$ & $\begin{array}{c}\text { Viscosity } \\
(\mathbf{m P a} \cdot \mathbf{s})\end{array}$ & $\begin{array}{c}\text { Polymerization degree } \\
(\mathbf{g} / \mathbf{m o l})\end{array}$ & $\begin{array}{c}\text { Melting point } \\
\left({ }^{\circ} \mathbf{C}\right)\end{array}$ & $\begin{array}{c}* \text { Ratio of modified } \\
\text { sulfur }(\%)\end{array}$ \\
\hline NS & 1.75 & 0.045 at $85{ }^{\circ} \mathrm{C}$ & $300-1200$ & 80 & 99.3 \\
\hline
\end{tabular}

* Ratio of modified sulfur was measured by using gel permeation chromatography.

Table 4. Physical properties of aggregates.

\begin{tabular}{ccccc}
\hline Type & Maximum size $(\mathbf{m m})$ Specific gravity & Fineness modulus Water absorption $(\mathbf{\%})$ \\
\hline Fine aggregate & - & 2.6 & 2.99 & 2.9 \\
\hline Coarse aggregate & 20 & 2.63 & 7.03 & 1.01 \\
\hline
\end{tabular}


Table 5. Physical properties of superplasticizer.

\begin{tabular}{cccc}
\hline Specific gravity $(\mathbf{g} / \mathbf{m L}) \mathbf{p H}$ value Temperature stability $\left({ }^{\circ} \mathbf{C}\right)$ & Usage $(\mathbf{\%})$ \\
\hline $120 \pm 0.2$ & $7 \pm 2$ & $5-50$ & $* \mathrm{C} \times(0.1-3.0)$ \\
\hline & $* \mathrm{C}$ is cement weight.
\end{tabular}

\subsection{Mixture Proportion}

The target slump and air content of concrete were considered to be $150 \pm 25 \mathrm{~mm}$ and $5.0 \%$, respectively. While the sand-aggregate ratio (S/a) of $45 \%$ and amount of water (W) of $185 \mathrm{~kg} / \mathrm{m}^{3}$ were fixed, the variables are summarized as follows: (1) water-cement ratios (W/C) of $40 \%, 45 \%$, and $50 \%$ and (2) MSCA-cement weight ratios of $0 \%, 5.0 \%, 7.5 \%$, and $10.0 \%$. Note that " $\mathrm{R}$ " in the mixture column represents the $\mathrm{W} / \mathrm{C}$, "CON" is the control mixture with uncoated crushed aggregate, "NS" is the modified sulfur used to coat the aggregate surface, and a final Arabic numeral is the modified sulfur-cement weight ratio. The detailed concrete mixing designs are given in Table 6. In R40 admixture series, $7.5 \%$ and $10 \%$ MACAs had negative effects on the mechanical properties of concrete, which made the coating treatment meaningless. So the mixtures with $7.5 \%$ and $10 \%$ MSCAs in R45 and R50 admixture series were not considered.

Table 6. Mix proportions of concrete mixtures.

\begin{tabular}{|c|c|c|c|c|c|c|c|c|c|}
\hline \multirow{2}{*}{ Mixture } & \multirow{2}{*}{$\mathrm{W} / \mathrm{C}(\%)$} & \multirow{2}{*}{ S/a $(\%)$} & \multirow{2}{*}{$\operatorname{Air}(\%)$} & \multicolumn{5}{|c|}{ Unit weight $\left(\mathrm{kg} / \mathrm{m}^{3}\right)$} & \multirow{2}{*}{$\begin{array}{l}\text { Sulfur } \\
(\mathbf{C} \%)\end{array}$} \\
\hline & & & & $\mathbf{W}$ & $\mathbf{C}$ & $\mathbf{S}$ & $\mathbf{G}$ & AD & \\
\hline $\mathrm{R} 40-\mathrm{CON}$ & \multirow{4}{*}{40} & \multirow{4}{*}{45} & \multirow{4}{*}{5} & \multirow{4}{*}{185} & \multirow{4}{*}{462} & \multirow{4}{*}{737} & \multirow{4}{*}{917} & 2.5 & 0.0 \\
\hline R40-NS5 & & & & & & & & 4.3 & 5.0 \\
\hline R40-NS7.5 & & & & & & & & 4.6 & 7.5 \\
\hline R40-NS10 & & & & & & & & 4.9 & 10.0 \\
\hline $\mathrm{R} 45-\mathrm{CON}$ & \multirow{2}{*}{45} & \multirow{2}{*}{45} & \multirow{2}{*}{5} & \multirow{2}{*}{185} & \multirow{2}{*}{411} & \multirow{2}{*}{756} & \multirow{2}{*}{942} & 2.2 & 0.0 \\
\hline R45-NS5 & & & & & & & & 3.7 & 5.0 \\
\hline $\mathrm{R} 50-\mathrm{CON}$ & \multirow{2}{*}{50} & \multirow{2}{*}{45} & \multirow{2}{*}{5} & \multirow{2}{*}{185} & \multirow{2}{*}{370} & \multirow{2}{*}{771} & \multirow{2}{*}{961} & 1.0 & 0.0 \\
\hline R50-NS5 & & & & & & & & 3.1 & 5.0 \\
\hline
\end{tabular}

W—water; C—cement; S—sand; a—aggregate; G—gravel; and AD—superplasticizer.

\subsection{Specimen Preparation}

Figure 10 illustrates the mixing procedure of the concrete with coated aggregate: (1) the coarse and fine aggregates were mixed for $15 \mathrm{~s}$; (2) the melted sulfur was added and mixed to coat the aggregate surface at a speed of $20 \mathrm{rpm}$ for $120 \mathrm{~s}$; (3) the cement was added and dry-mixed with the coated aggregate for $30 \mathrm{~s}$; and (4) finally, fresh concrete was made after mixing with the water and superplasticizer for $60 \mathrm{~s}$. A fan-type mixer was used during mixing procedure. Concrete cylinders with dimensions of $\phi 100 \mathrm{~mm} \times 200 \mathrm{~mm}$ were made for the measurement of the compressive strength and sulfate resistance of the proposed concrete mix. Prism beam specimens with dimensions of $100 \mathrm{~mm} \times 100 \mathrm{~mm} \times 400 \mathrm{~mm}$ were also prepared for the flexural strength test, freezing-thawing and length change. The concrete cylinders and prism beams were cast in plastic and steel molds, respectively. After the concrete was poured in the molds, the molds were vibrated using the vibrating 
table. The specimens were wrapped with plastic sheeting to prevent moisture evaporation, and they were kept in the curing room at the temperature of $23 \pm 2{ }^{\circ} \mathrm{C}$ and average relative humidity of $85 \%$. When $24 \pm 4 \mathrm{~h}$ passed, all specimens were demolded and water-cured until the various testing days.

Figure 10. Concrete mixing method: (a) mixing procedures; (b) mixing of aggregate; (c) addition of modified sulfur; (d) dry mix; and (e) addition of water and superplasticizer.

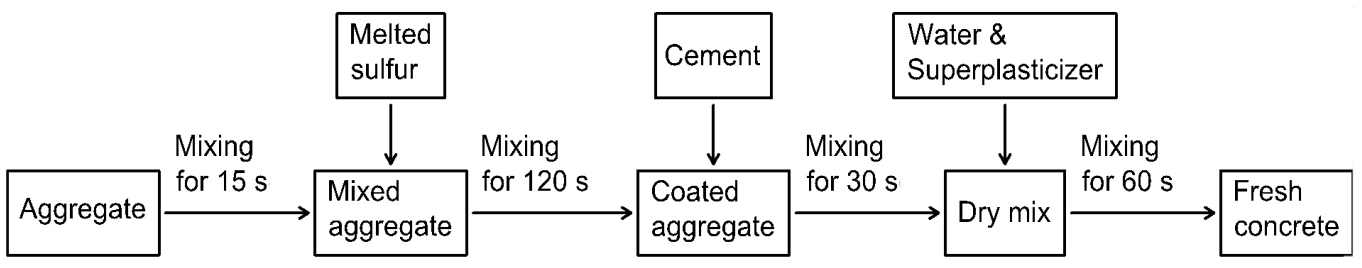

(a)

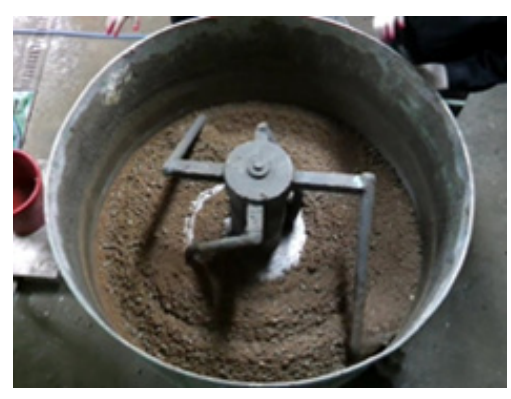

(b)

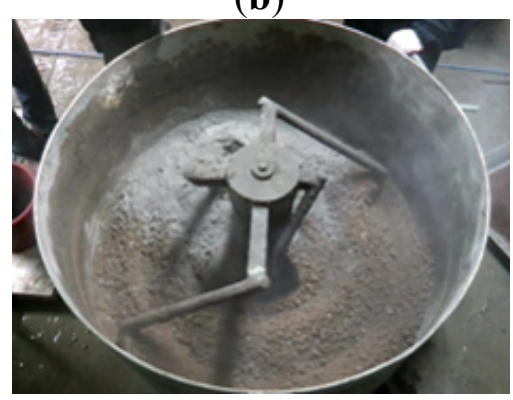

(d)

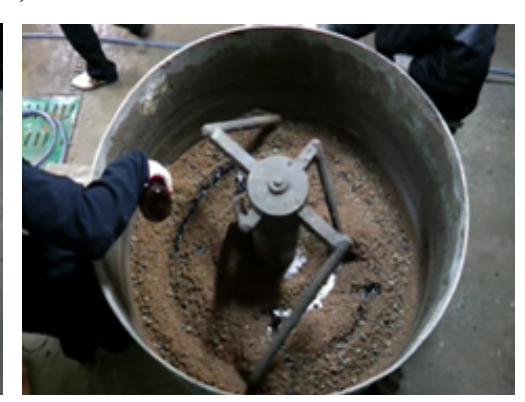

(c)

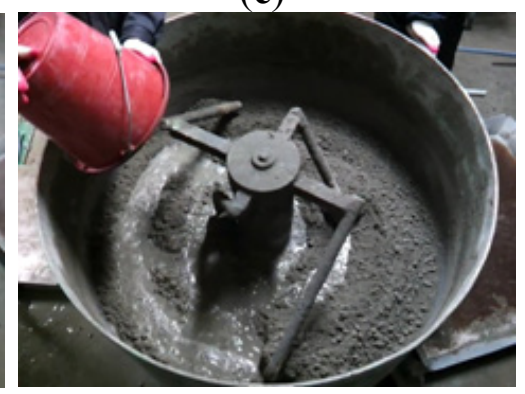

(e)

Distribution of sulfur on the surrounding aggregate was investigated by pictures taken after splitting failure, as shown in Figure 11. The modified sulfur was well-distributed all over the concrete and yellow color of concrete with MSCA became thicker with the higher amount of modified sulfur at the MSCA.

\subsection{Tests}

The water absorption, total porosity, and bulk density of the hardened MSCA concrete were determined after 28 days of curing in accordance with requirement of ASTM C642 [24]. A compressive strength test was carried out according to the ASTM C39/C39M [25] at 7, 28, and 56 days after manufacturing the specimens. A universal test machine (UTM) with the capacity of $2000 \mathrm{kN}$ was used for loading (see Figure 12a). The flexural strength was also measured according to the ASTM C78/C78M [26] using a load-cell with a range of $200 \mathrm{kN}$ at 28 and 56 days (see Figure 12b). 
Figure 11. Fracture surfaces of (a) R40-CON; (b) R40-NS5; (c) R40-NS7.5; and (d) R40-NS10 cylinders after splitting test.

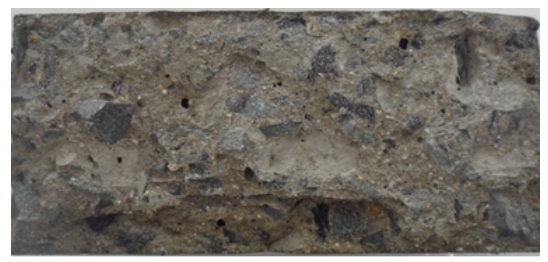

(a)

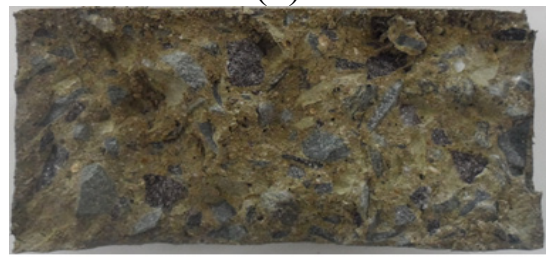

(c)

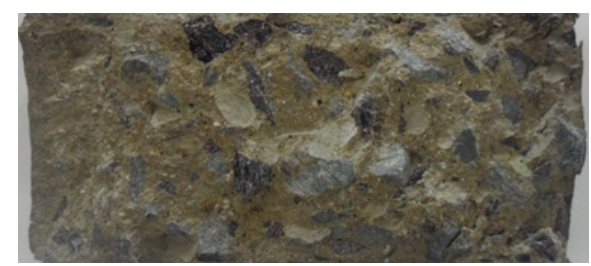

(b)

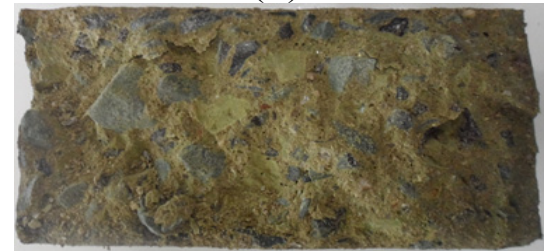

(d)

Figure 12. Test setup of (a) compressive strength; (b) flexural strength; (c) length change; and (d) dynamic modulus of elasticity.

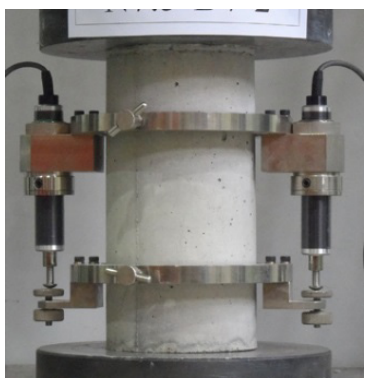

(a)

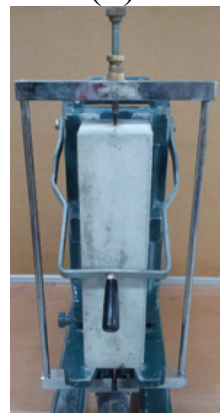

(c)

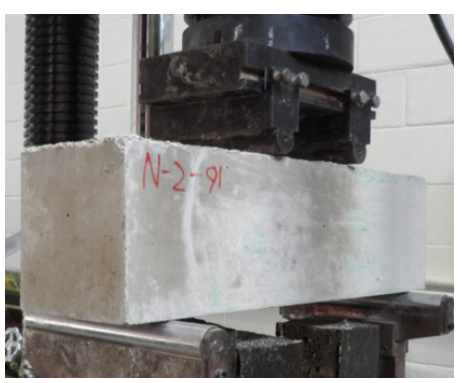

(b)

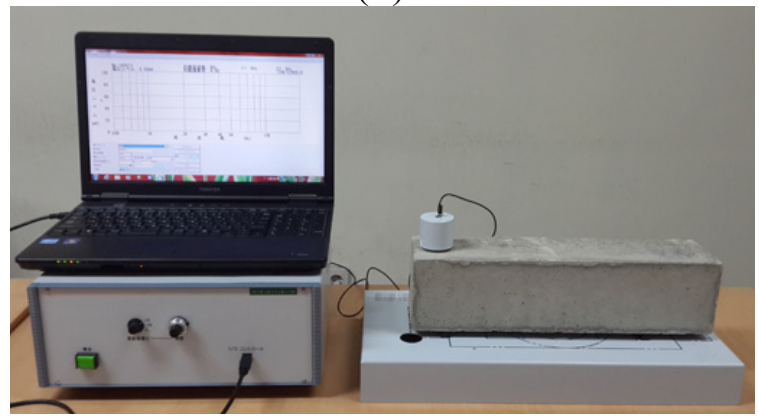

(d)

The length change of the prism specimen, as shown in Figure 12c, was evaluated by the comparator dial method in ASTM C157/C157M [27]. The data were recorded at 1 day intervals up to 7 days and continuously at 7 days intervals from 7 to 56 days. The resistance of the concrete to accelerate freezing and thawing in the prism specimens was carried out in accordance with ASTM C666/C666M [28]. The nominal freezing-and-thawing cycle for this test method consisted of alternately lowering the temperature of the specimens from $4 \pm 2$ to $-18 \pm 2{ }^{\circ} \mathrm{C}$ and raising it from $-18 \pm 2$ to $4 \pm 2{ }^{\circ} \mathrm{C}$ in $4 \mathrm{~h}$. The weight and dynamic modulus of elasticity were measured at 30 cycle intervals for a total of 300 cycles. Figure $12 \mathrm{~d}$ shows the test set up to measure the dynamic modulus of elasticity of a concrete beam after freezing-and-thawing cycles. 
The sulfate attack resistance performance of the concrete was observed according to JSTM C7401 [29]. The concrete cylinder samples with dimensions $\phi$ f00 $\mathrm{mm} \times 200 \mathrm{~mm}$ were deeply immersed in $5 \% \mathrm{H}_{2} \mathrm{SO}_{4}$ solution at $20 \pm 2{ }^{\circ} \mathrm{C}$. The weight of the specimens before and after immersion was measured on a digital laboratory scale with a capacity of $5 \mathrm{~kg}$ and accuracy of $0.01 \mathrm{~g}$ every 7 days. The averaged data from three specimens of each mixture is used in next section of post-analysis and discussion.

\section{Conclusions}

In this paper, the use of aggregate coated with modified sulfur was proposed as a constructional material. Based on various experiments carried out using concrete specimens made with modified sulfur coated aggregate (MSCA), the following mechanical properties and durability were observed:

1. The greater the amount of modified sulfur used to coat the aggregate, the lower the compressive strength of the concrete was. This is because the modified sulfur remaining after coating can act as impurities or light-weight aggregate in the concrete. Five percent modified sulfur of MSCA barely affected the flexural strength of the concrete regardless of the water-cement ratio, while addition of more than $7.5 \%$ of modified sulfur led to quickly decreased strength.

2. Use of MSCA in concrete slightly reduced the length change of concrete as compared with concrete not having MSCA, but the change rates did not significantly differ with variation of the melted amount of sulfur in the MSCA.

3. Also, the MSCA considerably improved the resistance to freezing-thawing and sulfuric acid because its use resulted in high porosity and prevented a chemical reaction between acid and basic oxides. The dosage of sulfur, however, did not greatly affect the resistance.

4. Amounts of modified sulfur exceeding 5\% had bad effects on mechanical strength through a compressive and flexural test. And the modified sulfur enhanced the durability in sulfuric acid and freezing-thawing, whereas the improvement did not strikingly vary according to the amount of modified sulfur. Synthetically, in terms of improvement of durability, using 5\% modified sulfur was suggested restrictively in the MSCA concrete.

\section{Acknowledgments}

This work was supported by a research grant of the Chungbuk National University in 2012.

\section{Author Contributions}

Jae-Kyu Park and Jung Ko conducted the experiments and wrote the initial draft of the manuscript. Ki-Nam Hong and Swoo-Heon Lee analyzed the data and wrote the final manuscript. All authors contributed to the analysis of the data and read the final paper.

\section{Conflicts of Interest}

The authors declare no conflict of interest. 


\section{References}

1. Neville, A.M. Properties of Concrete, 4th ed.; Pearson Education Limited: England, UK, 2008.

2. Wang, X.; Nguyen, M.; Stewart, M.G.; Syme, M.; Leitch, A. Analysis of Climate Change Impacts on the Deterioration of Concrete Infrastructure-Part 1: Mechanisms, Practices, Modelling and Simulations-A Review; CSIRO: Canberra, Australia, 2010.

3. Wang, X.; Nguyen, M.; Stewart, M.G.; Syme, M.; Leitch, A. Analysis of Climate Change Impacts on the Deterioration of Concrete Infrastructure-Part 2: Modelling and Simulation of Deterioration and Adaptation Options; CSIRO: Canberra, Australia, 2010.

4. Wang, X.; Nguyen, M.; Stewart, M.G.; Syme, M.; Leitch, A. Analysis of Climate Change Impacts on the Deterioration of Concrete Infrastructure-Part 3: Case Studies of Concrete Deterioration and Adaptation; CSIRO: Canberra, Australia, 2010.

5. Wang, X.; Nguyen, M.; Stewart, M.G.; Syme, M.; Leitch, A. Analysis of Climate Change Impacts on the Deterioration of Concrete Infrastructure-Synthesis Report; CSIRO: Canberra, Australia, 2010 .

6. Ajdukiewicz, A.; Kliszczewicz, A. Influence of recycled aggregates on mechanical properties of HS/HPC. Cem. Concr. Compos. 2002, 24, 269-279.

7. Mohamed, A.M.; El Gamal, M.M. Solidification of cement kiln dust using sulfur binder. J. Hazard. Mater. 2011, 192, 576-584.

8. Sagoe-Crentsil, K.K.; Brown, T.; Taylor, A.H. Performance of concrete made with commercially produced coarse recycled concrete aggregate. Cem. Concr. Res. 2011, 31, 707-712.

9. Sandrolini, F.; Saccani, A. The effect of polymer addition on the electrical behavior of ordinary and pulverized fly ash modified cement mortars. Mater. Struct. 1997, 30, 412-417.

10. Bacon, R.F.; Davis, H.S. Recent advances in the American sulfur industry. Chem. Metall. Eng. 1921, 24, 65-72.

11. Beaudoin, J.J.; Feldmant, R.F. Durability of porous systems impregnated with dicyclopentadiene-modified sulfur. Int. J. Cem. Compos. Lightweight Concr. 1984, 6, 13-17.

12. Bordoloi, B.K.; Pierce, E.M. Plastic sulfur stabilization by copolymerization of sulfur with dicyclopentadiene. Adv. Chem. Ser. 1978, 165, 31-53.

13. Lin, S.-L.; Lai, J.S.; Chian, E.S.K. Modification of sulfur polymer cement (SPC) stabilization and solidification (S/S) process. Waste Mang. 1995, 15, 441-447.

14. American Concrete Institute (ACI) Committee. Guide for Mixing and Placing Sulfur Concrete in Construction (Report 548.2R-93); American Concrete Institute (ACI) Committee: Farmington Hills, MI, USA, 1993.

15. Grugel, R.N.; Toutanji, H. Sulfur concrete for lunar applications-sublimation concerns. Adv. Space Res. 2008, 41, 103-112.

16. Mohamed, A.-M.O.; El Gamal, M. Hydro-mechanical behavior of a newly developed sulfur polymer concrete. Cem. Concr. Compos. 2009, 31, 186-194.

17. Thomas, C.; Cimentada, A.; Polanco, J.A.; Setién, J.; Méndez, D.; Rico, J. Influence of recycled aggregates containing sulphur on properties of recycled aggregate mortar and concrete. Compos. B Eng. 2013, 45, 474-485. 
18. Vlahovic, M.M.; Martinovic, S.P.; Boljanac, T.D.; Jovanic, P.B.; Volkov-Husovic, T.D. Durability of sulfur concrete in various aggressive environments. Constr. Build. Mater. 2011, 25, 3926-3934.

19. Li, J.; Xiao, H.; Zhou, Y. Influence of coating recycled aggregate surface with pozzolanic powder on properties of recycled aggregate concrete. Constr. Build. Mater. 2009, 23, 1287-1291.

20. Kong, D.; Lei, T.; Zheng, J.; Ma, C.; Jiang, J.; Jiang, J. Effect and mechanism of surface-coating pozzalanics materials around aggregate on properties and ITZ microstructure of recycled aggregate concrete. Constr. Build. Mater. 2010, 24, 701-708.

21. Morin, V.; Moevus, M.; Dubois-Brugger, I.; Gartner, E. Effect of polymer modification of the paste-aggregate interface on the mechanical properties of concretes. Cem. Concr. Res. 2011, 41, 459-466.

22. Zhihui, Z.; Shoude, W; Lingchao, L.; Chenchen, G. Evaluation of pre-coated recycled aggregate for concrete and mortar. Constr. Build. Mater. 2013, 43, 191-196.

23. Standard Test Method for Density, Relative Density (Specific Gravity), and Absorption of Fine Aggregate (ASTM C128); American Society for Testing and Material (ASTM) International: West Conshohocken, PA, USA, 2012.

24. Standard Test Method for Density, Absorption, and Voids in Hardened Concrete (ASTM C642); American Society for Testing and Material (ASTM) International: West Conshohocken, PA, USA, 2013.

25. Standard Test Method for Compressive Strength of Cylinder Concrete Specimens (ASTM C39/C39M); American Society for Testing and Material (ASTM) International: West Conshohocken, PA, USA, 2012.

26. Standard Test Method for Flexural Strength of Concrete (Using Simple Beam with Third-Point Loading) (ASTM C78/C78M); American Society for Testing and Material (ASTM) International: West Conshohocken, PA, USA, 2010.

27. Standard Test Method for Length Change of Hardened Hydraulic-Cement Mortar and Concrete (ASTM C157/C157M); American Society for Testing and Material (ASTM) International: West Conshohocken, PA, USA, 2008.

28. Standard Test Method for Resistance of Concrete to Rapid Freezing and Thawing (ASTM C666/C666M); American Society for Testing and Material (ASTM) International: West Conshohocken, PA, USA, 2008.

29. Japan Society for Testing Materials (JSTM). Chemical Resistance Test Method of Concrete by Solution Immersion (JSTM C7401); Japan Testing Center for Construction Materials: Tokyo, Japan, 1999. (In Japanese)

(C) 2014 by the authors; licensee MDPI, Basel, Switzerland. This article is an open access article distributed under the terms and conditions of the Creative Commons Attribution license (http://creativecommons.org/licenses/by/3.0/). 